\title{
Correction to: Thinking Innovatively About Innovation Research
}

\author{
Andrew Sixsmith, Judith Sixsmith, Alex Mihailidis, and Mei Lan Fang
}

\section{Correction to:}

Chapter 2 in: A. Sixsmith et al. (eds.), Knowledge, Innovation, and Impact: A Guide for the Engaged Health Researcher, International Perspectives on Social Policy, Administration, and Practice, https://doi.org/10.1007/978-3-030-34390-3_2

The original version of this chapter was revised due to a typo in the reference section (page -16).

On pg. 16 - 2nd reference had Jen Boger's last name spelled as “Borger."

The correct reference is given below

Boger, J., Jackson, P., Mulvenna, M., Sixsmith, J., Sixsmith, A., ... Martin, S. (2017). Principles for fostering the transdisciplinary development of assistive technologies. Disability and Rehabilitation: Assistive Technology, 12(5), 480-490.

The updated online version of this chapter can be found at https://doi.org/10.1007/978-3-030-34390-3_2 